\title{
ADOÇÃO DE SOCIAL COMMERCE: CAMINHOS VÁLIDOS PARA O ALCANCE DA INTENÇÃO DE COMPRA EM MÍDIAS SOCIAIS NO CONTEXTO BRASILEIRO
}

\author{
SOCIAL COMMERCE ADOPTION: VALID WAYS TO REACH THE PURCHASE
} INTENTION IN SOCIAL MEDIA IN THE BRAZILIAN CONTEXT

Larissa Soares de Queiroz Rios

Universidade Federal de Sergipe - Brasil.

larissasoares.lsq@gmail.com

Maria Conceição Melo Silva Luft

Universidade Federal de Sergipe - Brasil.

ceica@infonet.com.br
Submissão: 10/1//20/8. Aceitação: 01/10/2019.

Publicação: 30/12/2019. Sistema de avaliação: Double

blind review. Universidade FUMEC / FACE, Belo Horizon-

te - MG, Brasil. Editores Prof. Dr. Mário Teixeira Reis Neto

- Prof. Dr. Cid Gonçalves Filho.

\section{RESUMO}

Este estudo buscou validar uma proposta teórica para a adoção de social commerce que resulte na intenção de compra em mídias sociais por parte dos usuários brasileiros. $O$ referencial teórico explanou histórico, conceitos e características do social commerce e fatores influenciadores ou resultantes do comportamento do usuário para a adoção de social commerce, evidenciando o modelo de pesquisa proposto. Participaram da pesquisa 232 usuários do Facebook que buscam informações sobre produtos em mídias sociais e são consumidores online. Os dados obtidos foram submetidos a análise fatorial confirmatória e os resultados indicaram que a estrutura do modelo teórico é compreensível e válida para os consumidores brasileiros, de modo que os critérios de confiabilidade e validade convergente e discriminante foram atingidos sem a eliminação de itens ou modificação das variáveis. Consequentemente, evidencia-se a força das variáveis estudadas e do potencial do modelo para a mensuração de tal intenção de compra.

\section{PALAVRAS-CHAVE}

Social commerce. Mídias sociais.Adoção de tecnologia. Intenção de compra.Análise fatorial confirmatória. 


\section{ABSTRACT}

This study sought to validate a theoretical proposal for the adoption of social commerce that results in the intention to buy in social media by Brazilian users. The theoretical framework explained the history, concepts and characteristics of social commerce and factors influencing or resulting from user behavior for the adoption of social commerce, evidencing the proposed research model.The survey was attended by 232 Facebook users who are looking for information on social media products and are consumers online. The data obtained were submitted to a confirmatory factorial analysis and the results indicated that the structure of the theoretical model is comprehensible and valid for the Brazilian consumers, so that the criteria of reliability and convergent and discriminant validity were achieved without the elimination of items or modification of the variables. Consequently, the strength of the studied variables and the potential of the model for the measurement of such purchase intention is evidenced.

\section{KEYWORDS}

Social commerce. Social media. Adoption of technology. Buy intention. Confirmatory factorial analysis.

\section{INTRODUÇÃO}

Ao longo do tempo, os sistemas de informação (SI) mudaram significativamente as formas de comunicação, interação, trabalho e/ou entretenimento dos indivíduos (MALITA, 20II; NGAl et al, 20I5). Transformações econômicas, políticas, sociais e culturais são vivenciadas por meio de iniciativas que visam a ampliação da adoção de tecnologia por parte das pessoas, governos, organizações, empresas e mercados (CGI, 20l8). Diante disso, a Web 2.0 e o surgimento das mídias sociais representaram um dos impactos mais transformadores da tecnologia, mudando o modo como as pessoas se comunicam e colaboram, bem como a forma como os negócios são conduzidos (HUANG; BENYOUCEF, 20I3; TODRI; ADAMOPOULOS, 20I4; BUSALIM; HUSSIN, 2016).

No Brasil, as atividades realizadas na in- ternet por indivíduos das mais diversas faixas etárias e classes sociais concentram-se fortemente na geração de conteúdo online por meio do envio de mensagens instantâneas e no uso das mídias sociais (CGI, 2018). Nessa perspectiva, dados do relatório Digital in 2018 in Southern America relevam que há cerca de 130 milhões de usuários brasileiros ativos de mídias sociais, que as utilizam diariamente por um tempo médio de 3 horas e 39 minutos. Tal quantidade de usuários consiste em aproximadamente $62 \%$ da população nacional e teve crescimento anual médio de $7 \%$ para novos adotantes (HOOTSUITE, 20I8).

Este cenário aponta a relevância das mídias sociais na vida cotidiana e alerta as organizações para os desafios e oportunidades decorrentes do comportamento dos usuários, afinal a aplicação das mídias sociais para as empresas torna-se similar 
à de outros sistemas de informação (Ngai, Tao \& Moon, 20 I5). Na esteira desses fatos, à medida que a popularidade das mídias sociais é crescente entre os internautas, as relações sociais online os encoraja à participação ativa em ações cada vez mais variadas, incluindo atividades comerciais (CHEN et al, 20 I3; Hajli, 20 I4, 20 I5).

Tais mudanças resultam na configuração do social commerce cuja estrutura comercial sofre uma orientação social e os consumidores ganham maior compreensão de um produto por meio da colaboração (HAJLI, 20l4b; TURBAN; STRAUSS; LAI, 2016). Logo, o social commerce consiste na junção de atividades comerciais e sociais em infraestruturas tecnológicas que suportem os processos de interação e cooperação dos usuários para obtenção de produtos (LIANG; TURBAN, 20II). Consequentemente, influências das mídias sociais no comportamento do usuário/consumidor do comércio social incluem: conscientização, aquisição de informações, opiniões, atitudes, intenção e comportamento de compra, assim como comunicação e avaliação pós-compra (MANGOLD; FAULDS, 2009).

Diante disso, várias empresas começaram a usar websites de redes sociais, dentre outros tipos de plataformas de mídias sociais, inicialmente como um meio de publicidade online. Porém, na perspectiva atual, tais tecnologias são utilizadas como meio de interação com os clientes e estímulo à intenção de compra, começando a reconhecer as oportunidades estratégicas que emergem nesses avanços tecnológicos e as mudanças subsequentes no comportamento dos internautas (HAJLI, 20 I4b; TODRI; ADAMOPOULOS, 20I4; BUSALIM; HUSSIN, 2016).

Diversas plataformas de mídias sociais que agregam o comércio social surgiram na China (ex.: renren.com, us.weibo.com), no Japão (ex.: mixi.jp), na Europa (ex.: vk.com), na América Latina (hi5.com) e na Indonésia (ex.: kaskus.co.id), dentre outras localidades (ZHANG et al, 20I4; DZAHABAN; SHIHAB, 2016; TURBAN et al, 2018). Pequenas e grandes empresas veem a oportunidade de viabilizar seus negócios no comércio social, de modo que várias startups surgiram nesta geração de comércio eletrônico e negócios estabelecidos têm demonstrado pretensão de investimento no social commerce (LIANG; TURBAN, 20II; GALINARI et al, 20I5; BUSALIM; HUSSIN, 20I6).

No cenário brasileiro, o comércio social ainda é um fenômeno emergente. Com perspectivas positivas de crescimento a partir da aceitação das mídias sociais por parte dos negócios digitais, há maiores possibilidades de empreendedorismo informal online e geração de atividades comerciais entre consumidores (ROSA; DOLCI; LUNARDI, 20I4; GALINARI et al, 20I5; E-BIT, 20I8).

Perante as perspectivas emergentes do social commerce no Brasil, esta pesquisa avalia tal fenômeno por meio da intenção de compra dos consumidores (usuários), visto que o conteúdo gerado por meio de componentes dispostos nas mídias sociais pode promover experiências positivas para o consumidor online e influenciar a geração de confiança em atividades comerciais realizadas no ambiente online. Diante do exposto, a pesquisa pretende verificar a validação de uma proposta teórica para a adoção de social commerce, baseada em Hajli (20I5) e Dzahaban e Shihab (2016), que resulte na intenção de compra em mídias sociais por parte dos usuários brasileiros.

Portanto, a estrutura sequencial da pesquisa é subdividida em cinco seções. A pri- 
meira seção aborda o social commerce em termos de histórico, conceitos e caracteristicas. A segunda seção discute aspectos relacionados ao comportamento do usuário para adoção de social commerce, desencadeando o modelo de pesquisa proposto. A terceira seção discorre sobre as escolhas metodológicas para a validação do modelo de pesquisa em uma amostra brasileira. A quarta seção analisa os resultados encontrados para as etapas de validação testadas e, por fim, a quinta seção apresenta as conclusões do estudo em termos de contribuições e limitações dos achados, assim como as possibilidades de futuras pesquisas.

\section{SOCIAL COMMERCE}

No comércio social (social commerce ou s-commerce), as pessoas exploram intencionalmente oportunidades de comércio, participando e/ou se envolvendo em um ambiente colaborativo online (CURTY; ZHANG, 20I I). Este fenômeno reúne três componentes-chave: tecnologias da Web 2.0, mídias sociais e comércio eletrônico (BUSALIM; HUSSIN, 20I6; TURBAN et al, 20I8; TURBAN, STRAUSS; LAI, 20I6), de modo a ser comumente visto como um novo patamar de e-commerce gerado pela popularidade usual das mídias sociais e que concede maior empoderamento ao consumidor online para criação de conteúdo (LIANG;TURBAN, 20 I I; LIANG et al, 20 I I; HAJLI, 20 I5;TURBAN et al, 20 I8).

Liang et al (20II) explicam que a principal característica do comércio social se encontra no aproveitamento do capital social online por meio das mídias sociais, visto que os usuários são comumente encorajados ao compartilhamento de informações sobre produtos com sua rede social virtual e/ou a venda de produtos/serviços. Desta forma, o social commerce pode ser utilizado para combinar as abordagens de negócios online B2C (Business to Consumer) e C2C (Consumer to Consumer), de modo que os usuários obtenham a oportunidade de desempenhar várias funções simultaneamente, como comprador, vendedor e revisor; passando de receptores a produtores de informação (SAUNDAGE; LEE, 201 I; CURTY; ZHANG, 20II; ROSA; DOLCl; LUNARDI, 20I4).

O termo social commerce tornou-se amplamente reconhecido, no Brasil e no mundo, no ano de 2005 quando foi utilizado para descrever a ferramenta de compra online colaborativa do Yahoo!, que pretendia construir uma comunidade de compradores (Yahoo!'s Shoposphere) que criassem, compartilhassem, comentassem e avaliassem listas de produtos, sendo a informação disponibilizada para outros compradores (SAUNDAGE; LEE, 20II; WANG; ZHANG, 20I2; BUSALIM; HUSSIN, 2016). Em 2007 surgiram as primeiras publicações que usavam explicitamente a terminologia, ampliando o reconhecimento acadêmico e crescimento da área (FRIEDRICH, 20I5). Já no contexto das mídias sociais, o comércio social ganhou força em 2009 quando a primeira loja (I-800-Flowers.com) surgiu no Facebook (KAPLAN; HAENLEIN, 20 I 0; BUSALIM; HUSSIN, 20I6;TURBAN et al, 20I8).

Como um campo de estudos em crescimento, diversos autores e disciplinas esforçam-se para compreender e definir o comércio social, porém nenhuma definição generalista foi acordada assim como a extensão e os limites do fenômeno são pouco compreendidos (TURBAN; STRAUSS; LAI, 2016). Nesse sentido, a descrição do comércio social envolve múltiplas disciplinas, incluindo marketing, sistemas de informa- 
ção, sociologia e psicologia, que atribuem significados diversos ao fenômeno (BAGHDADI, 20I6).

O marketing enfoca o social commerce por meio dos esforços empresariais nas mídias sociais, como ferramenta de marketing direto, para apoiar o processo de decisão de compra. Para a disciplina sistemas de informação, o comércio social é descrito como a aplicação mediada por tecnologias da Web 2.0 e plataformas interativas, como websites de redes sociais e comunidades de conteúdo, para um ambiente comercial. $\mathrm{Na}$ sociologia, o comércio social consiste na utilização de comunidades web por empresas de e-commerce, focalizando o impacto da influência social na atividade comercial. Já a psicologia investiga como os usuários são influenciados por terceiros de uma comunidade em rede nas compras online (HUANG; BENYOUCEF, 20 I 3; CHEN; SHEN; CHEN, 20 I 4; BAGHDADI, 20I6).

Ademais, os conceitos gerados e adotados pelos estudiosos para a compreensão do social commerce são parcialmente distintos. Revisões de literatura realizadas sobre o tema acentuam ainda mais a existência de múltiplas definições. Marsden (20II) encontrou mais de vinte definições diferentes para o comércio social e Wang e Zhang (20I2) listaram onze definições. Já uma revisão sistemática realizada por Busalim e Hussin (2016), compreendendo estudos publicados de 2010 a 20I5, aponta a existência de quatorze definições distintas posicionando-se de modo a identificar o comércio social como representação da interatividade provocada pela Web 2.0 e ferramentas de computação que representam o aspecto social da atividade comercial. Tendo em vista as pesquisas supracitadas e o referencial teórico deste estudo, no in- tuito de evidenciar esta discussão teórica, - Quadro I resume o posicionamento de algumas das diversas contribuições acadêmicas para o conceito de social commerce.

Apesar de não haver um conceito padrão para o comércio social e das definições apontadas no Quadro I não serem exaustivas, este estudo adota a visão de Liang e Turban (20II) que também foi adotada por outros estudos da área (HAJL, 20I4b, 20I5; HAJLI et al, 2017). Portanto, considerando o até aqui exposto, as escoIhas teóricas permeiam para o conceito de s-commerce como a combinação de atividades comerciais e sociais, com o uso de tecnologias e infraestruturas da Web 2.0, para suportar interações online e contribuições dos usuários na aquisição de produtos e serviços (LIANG; TURBAN, 20II).

Nesse sentido, podem ser identificados dois elementos essenciais: mídias sociais e atividades comerciais, que devem estar incluídos em um evento ou website para que este seja considerado promotor do comércio social (LIANG;TURBAN, 20I I). Afinal, o objetivo principal do comércio social é combinar aspectos comerciais, informativos, tecnológicos e sociais, aproveitando os relacionamentos existentes nas redes sociais virtuais para obtenção de benefícios comerciais (WANG; ZHANG, 2012; LIANG et al, 20II; CHEN; SHEN; CHEN, 20I4).

\section{ADOÇÃO DE SOCIAL COMMERCE}

Os estudos sobre o comércio social têm se concentrado nos fundamentos conceituais do fenômeno e sua perspectiva histórica (LIANG; TURBAN, 20II; CURTY; ZHANG, 20I I; YADAV et al, 20I3), atividades comerciais e sociais, modelos de negócio emergentes (CHEN et al, 20I3; TODRI; ADA- 
QUADRO 1 - Conceitos de Social Commerce

\begin{tabular}{|c|c|}
\hline Antores & Deinilcile \\
\hline IBM (2009) & Boca-aboca integrailo e aplicado no comircio detrohico. \\
\hline $\begin{array}{l}\text { Marden (2011), Chen, } \\
\text { shen eChen (2014)e } \\
\text { Fijil (2014a). }\end{array}$ & 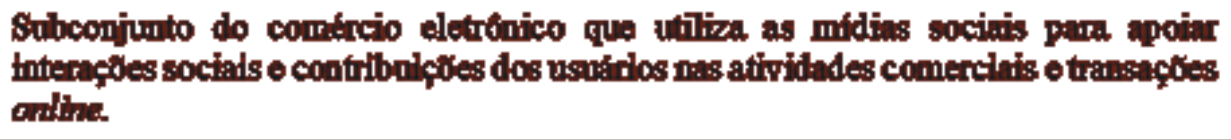 \\
\hline Wang a Zhax & 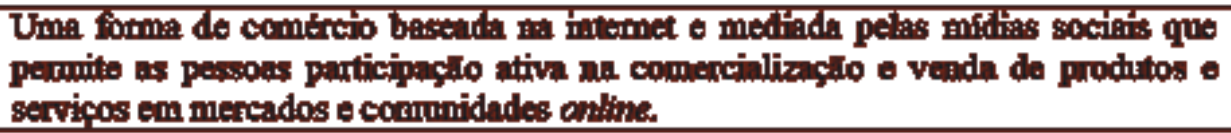 \\
\hline $\begin{array}{l}\text { Fingug e Bex } \\
\text { (2013) }\end{array}$ & 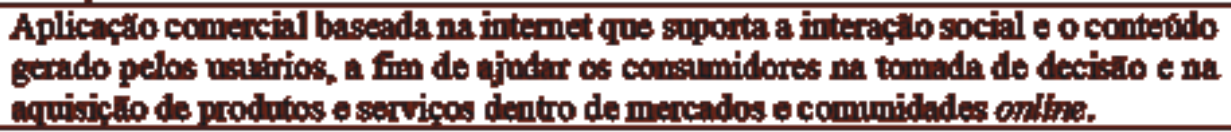 \\
\hline Yada & 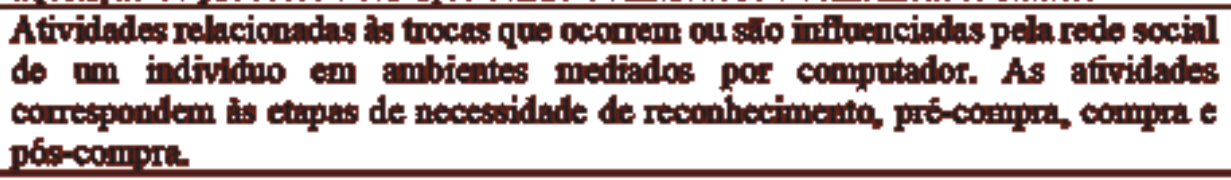 \\
\hline $\begin{array}{l}\text { Soares, Dolci } \\
\text { (2015) }\end{array}$ & 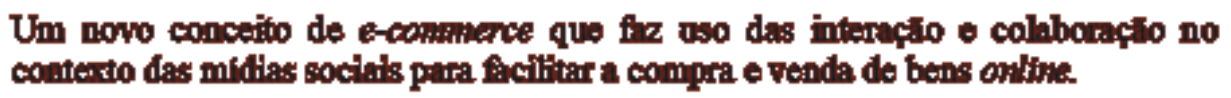 \\
\hline Baghdadi (2016) & 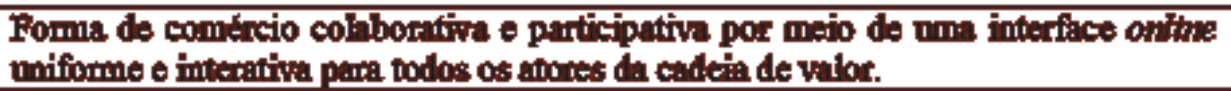 \\
\hline Lin; Li o Wang (2017) & 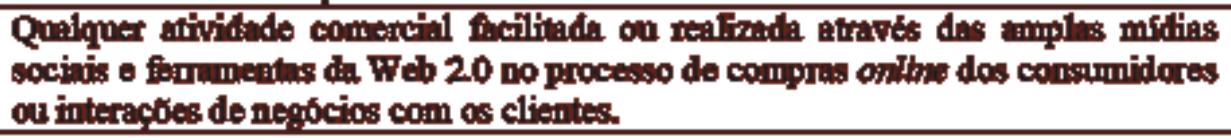 \\
\hline $\begin{array}{l}\text { Tuban, Strauss oLai } \\
\text { (2016) Turban et d } \\
\text { (2018) }\end{array}$ & 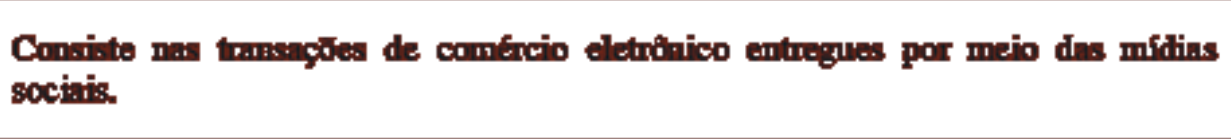 \\
\hline
\end{tabular}

Fonte: Elaborado pelas autoras (2019).

MOPOULOS, 20I4), segurança transacional (BARRETO, 20II), características tecnológicas e as estrutura de design do fenômeno (HUANG; BENYOUCEF, 20I3; WU et al, 20I5; BAGHDADI, 20I6) e o comportamento do usuário (KIM; PARK, 20 I3; HAJLI, 20I4a, 20 I 5; ZHANG et al, 20 I4; HAJLI et al, 20I7;DZAHABAN;SHIHAB, 20 I6; LU;FAN; ZHOU, 2016), dentre outras vertentes.

Mediante as possibilidades temáticas indicadas, a presente pesquisa enfoca o comportamento do usuário por acreditar que esta é uma corrente dominante no comércio social e ideal para exploração dos aspectos inerentes ao campo de Sistemas de Informação, tais como fatores influenciadores no processo de adoção e uso de tecnologia (FRIEDRICH, 20I5; LI, 20I7; LIN; LI;WANG, 2017).
$\mathrm{Na}$ investigação do comportamento do usuário, ressalta-se a importância de teorias e modelos relacionados à interação e ao processo social buscando o entendimento do comportamento do indivíduo (usuário/consumidor) e a previsão de resultados (LIANG; TURBAN, 20I I). De modo geral, as teorias básicas para adoção do comércio eletrônico e das mídias sociais também são usadas na explicação do processo de adoção do comércio social pelos consumidores (LIANG; TURBAN, 20II; WANG; ZHANG, 20I2; FRIEDRICH, 20I5; NGAI et al, 20I5). Nesse sentido, modelos teóricos amplamente testados no campo de Sl, tais como o modelo de aceitação de tecnologia (TAM) e a teoria do comportamento planejado (TPB) constituem as bases para apreciação empírica do social commerce (BUSALIM; HUSSIN, 20I6). 
Ademais, os pesquisadores de comércio eletrônico e/ou mídias sociais utilizam a combinação de teorias e modelos na investigação do comportamento sócio psicológico dos usuários (NGAl et al, 20I5;TURBAN et al, 20I8), o que também ocorre no campo do social commerce (por exemplo, ZHANG et al, 20I4; DZAHABAN; SHIHAB, 20 I6; SHANMUGAM et al, 20l6; MENTI et al. 20I7; LI, 20I7). Assim, outros apoios teóricos para o estudo do comportamento do usuário podem surgir por meio de relações entre teorias como capital social, psicologia social, comportamento do consumidor, colaboração online, entre outras (FRIEDRICH, 20I5;TURBAN; STRAUSS; LAI, 20 I6; TURBAN et al, 20l8).

Nesse sentido, um conjunto de variáveis influenciadoras para intenções e/ou comportamentos dos consumidores (usuários) em relação ao social commerce podem surgir, de modo que há necessidade de síntese das diversas concepções existentes, pois as descobertas empíricas estão espalhadas na base da literatura e às vezes não são transparentes ou diretamente comparáveis (FRIEDRICH, 20I5).

Diante disso, o Quadro 2 identifica algumas dentre as variáveis influenciadoras e resultantes mais utilizadas por estudos do campo de social commerce:

A diversidade de variáveis utilizadas pelos acadêmicos na pesquisa do comportamento do usuário desencadeia, portanto, o surgimento de múltiplos modelos e adaptações teóricas. Nesse sentido, a presente pesquisa apresenta uma proposta teórica proveniente da adaptação dos modelos de Hajli (20I5) e Dzahaban e Shihab (2016) para a compreensão da adoção de social commerce no contexto brasileiro.

QUADRO 2 - Variáveis Influenciadoras e Resultantes do Social Commerce

\begin{tabular}{|c|c|}
\hline \multicolumn{2}{|r|}{ 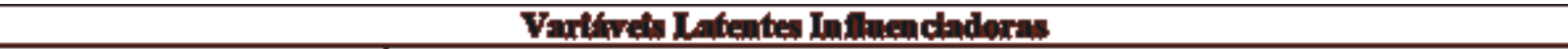 } \\
\hline Apoin Social & 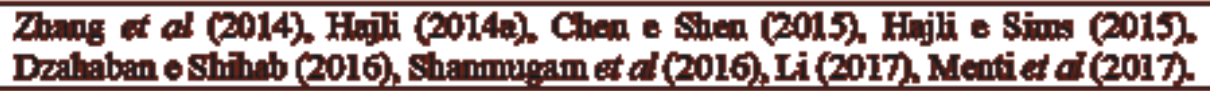 \\
\hline Confímç̧ & 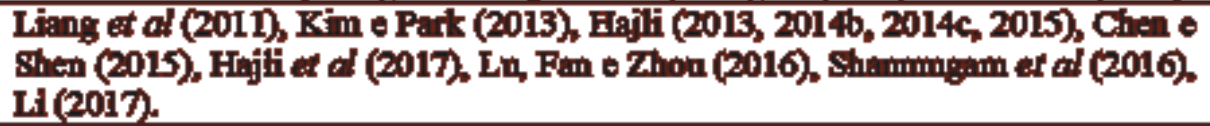 \\
\hline $\begin{array}{l}\text { Componeintes do sockl } \\
\text { Coinimer }\end{array}$ & 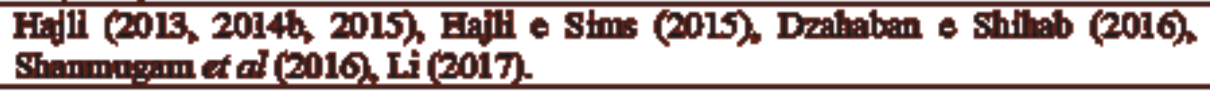 \\
\hline Famicininde & Hnilief (2017), Li(2017). \\
\hline Presenga Sowial & 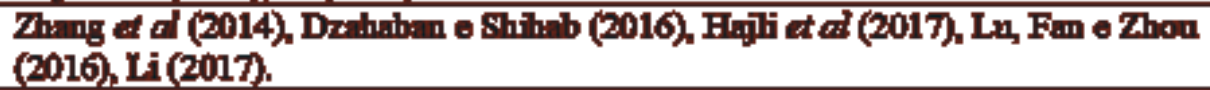 \\
\hline $\begin{array}{l}\text { Qratidado do } \\
\text { Relacionamento }\end{array}$ & Lang a ol (2011) Fiaji (2014a) \\
\hline 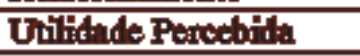 & Fin: 11 (2013, 2014b, 2014c) \\
\hline Outros & 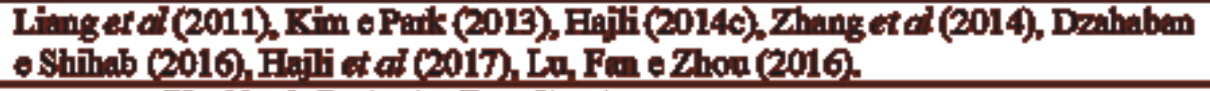 \\
\hline \multicolumn{2}{|r|}{ 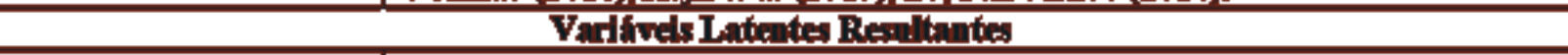 } \\
\hline $\begin{array}{l}\text { Infençito ou } \\
\text { compcrtamento de } \\
\text { compartilhamento }\end{array}$ & $\begin{array}{l}\text { Zhang et al (2014), Chen o Shen (2015), Dababen o Shinab (2016), Menti ot d } \\
\text { (2017). }\end{array}$ \\
\hline $\begin{array}{l}\text { Infencilo ou } \\
\text { compartamento de } \\
\text { comping }\end{array}$ & 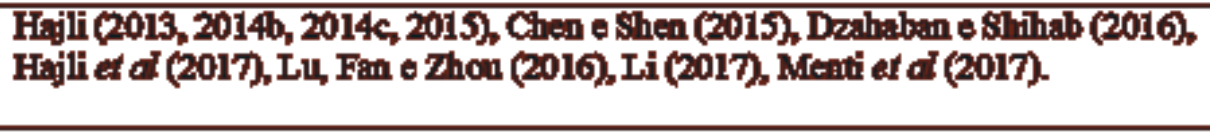 \\
\hline $\begin{array}{l}\text { Infencilo oul } \\
\text { compartamento de vso }\end{array}$ & Limg ef al (2011) Hajjh (20144) Hajli o sims (2015). \\
\hline Outros & Lianged d (2011), Kim o Fart (2013). \\
\hline
\end{tabular}

Fonte: Elaborado pela autora (2019) inspirado em Friedrich (2015). 
Acredita-se que a junção dos modelos teóricos (HAJLI, 20I5; DZAHABAN; SHIHAB, 2016) para a elaboração do modelo de pesquisa permite uma influência mais poderosa na formação da intenção de compra em contextos emergentes de comércio social. Ou seja, defende-se que a união das propostas permite um melhor entendimento da intenção de compra.

Consequentemente, o modelo proposto apresenta uma estrutura que relaciona seis variáveis latentes (construtos) que podem ser classificadas como variáveis antecessoras (componentes do social commerce), variáveis mediadoras (apoio social, presença social, fluxo e confiança) e variáveis resultantes (intenção de compra). Para Ngai et al (2015), variáveis antecessoras são estímulos que acompanham um resultado comportamental e estão sempre posicionados no lado de entrada da estrutura, as mediadoras são variáveis que explicam as relações causais entre antecessores e resultantes e as variáveis resultantes são as consequências esperadas e geradas por variáveis antecessoras, sob a influência de variáveis mediadoras. Desta forma, o modelo proposto é ilustrado na Figura I.
Ressalta-se que os componentes do social commerce buscam representar três ferramentas (recomendações e referências, avaliações e classificações, fóruns e comunidades) que podem ser consideradas como diferenciadores-chave do comércio social em comparação com outros ambientes de negócios online (HAJLI; FEATHERMAN, 2017). Nesse sentido, como variável antecessora, os componentes do social commerce (CSC) admitem a geração de conteúdo e capital social, a sociabilidade na atividade comercial e o aperfeiçoamento de experiências online que auxiliam os consumidores em seu comportamento de compra (DZAHABAN; SHIHAB, 20 I6; SHANMUGAM et al, 2016; HAJLI et al, 20I7; HAJLI; FEATHERMAN, 20 I7).

Com relação às variáveis mediadoras, estas são reconhecidas na literatura como formadoras da experiência do consumidor online, onde o apoio social refere-se à sensação de suporte informacional e emocional no contato com outros, a presença social representa a sensação de calor, proximidade e presença psicológica do indivíduo e de outros na rede social virtual

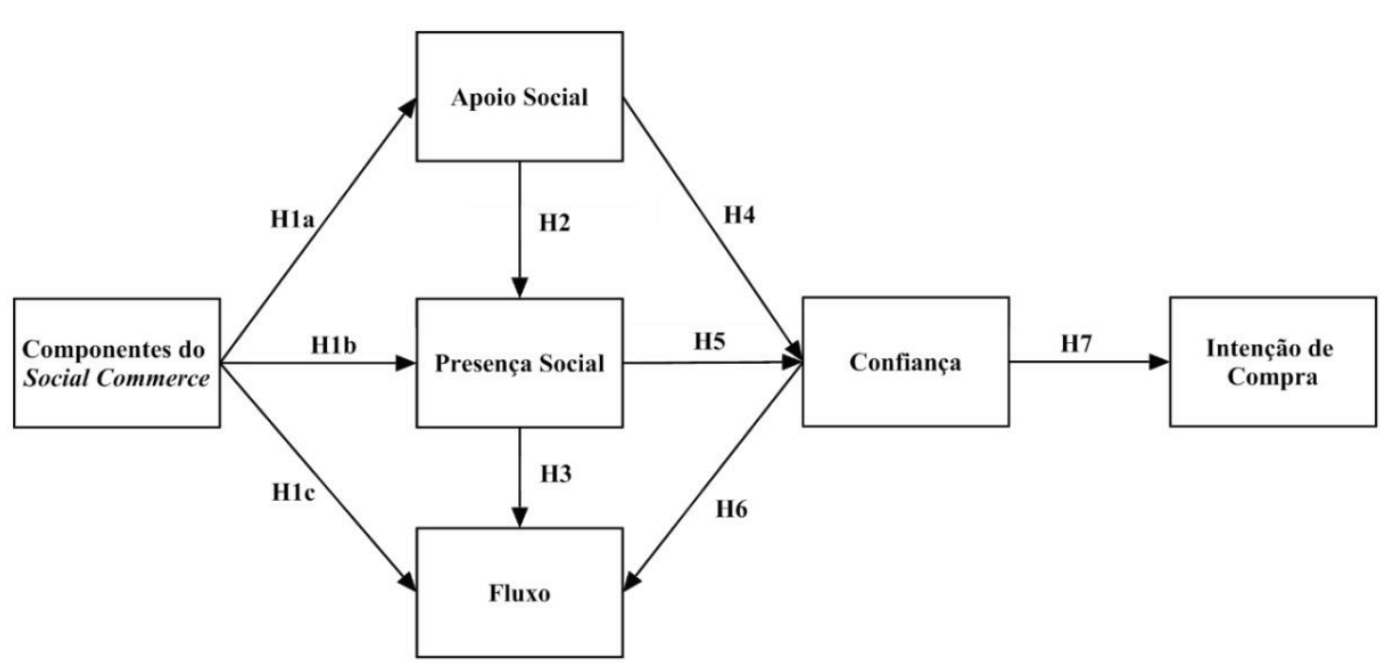

FIGURA 1 - Modelo de Pesquisa

Fonte: Adaptado de Hajli (2015) e Dzahaban e Shihab (2016). 
e o fluxo condiz a um estado de imersão em determinada atividade que possibilita $\circ$ comportamento exploratório e a perda de noção de tempo e espaço (LIANG et al, 20II; ZHANG et al, 20I4; DZAHABAN; SHIHAB, 20I6).

Ainda no processo de mediação para intenção de compra, a variável confiança consiste na benevolência e credibilidade em promessas e acordos feitos entre as partes (HAJLI, 20I5) enquanto, o resultado de intenção de compra é definido pela intenção de envolvimento em compras por meio das plataformas de mídias sociais (LIANG et al, 20I I; ZHANG et al, 20I4; HAJLI, 20I5).

$\mathrm{Na}$ busca por caminhos consistentes que permitam a validação do modelo de pesquisa proposto, a próxima seção apresenta as escolhas metodológicas feitas para o alcance de resultados empíricos.

\section{PROCEDIMENTOS METODOLÓGICOS}

A presente pesquisa abarca-se em uma filosofia positivista que enfatiza a abordagem quantitativa e técnicas estatísticas de análise multivariada. Assim tal pesquisa é caracterizada como descritiva e correlacional à medida que busca especificar ou medir características, propriedades, perfis de uma população, amostra ou fenômenos a serem mensurados e, de igual modo, conhecer a relação quantificada entre conceitos, categorias ou variáveis em um contexto sustentável (SAMPIERI; COLLADO; LÚCIO, 2006). Em termos de estratégia de pesquisa, optou-se pelo survey, ou seja, o questionamento direto de indivíduos representantes de uma população para obtenção de dados que permitam o alcance do objetivo traçado.

$\mathrm{Na}$ definição dos critérios populacio- nais, foram diagnosticados como elegíveis para a população os indivíduos que: (I) são usuários brasileiros ativos do Facebook que (2) realizaram pelo menos uma compra online no ano de 2018 e (3) utilizam suas redes sociais virtuais para obtenção de informações de compra, vendedores, experiências de pares etc., assemelhando-se de certa forma aos critérios estabelecidos no estudo de Menti et al. (2017).

$\mathrm{Na}$ impossibilidade de uma pesquisa censitária, optou-se por uma amostra não probabilística, por auto seleção, de modo que os potenciais respondentes tiveram acesso à divulgação da pesquisa e optaram voluntariamente por participar da mesma ao se sentirem envolvidos e/ou interessados pela temática (SAUNDERS; LEWIS;THORNHILL, 2009). Além do tipo de amostra também foi calculada uma estimativa no software G*Power, versão 3.1.9.2, com nível de significância de 0,05 , poder do teste (Power $=1-\beta$ err prob) de 0,80, tamanho de efeito $\left(f^{2}\right)$ em 0,15 e três preditores com base nas setas recebidas pelo construto Fluxo. O valor amostral foi de 77 casos, de modo que o tamanho amostral aceitável deve ser duplicado ou triplicado (I54 a 23 I indivíduos), conforme orientações de Hair et al (20|4) e Ringle, Silva e Bido (20I4).

A coleta de dados foi feita por meio de um questionário online, disponibilizado por meio de um link personalizado e divulgado com um banner e uma mensagem padrão sobre a pesquisa. $O$ questionário apresentava inicialmente um breve Termo de Consentimento Livre Esclarecido (TCLE) que indicava a finalidade da pesquisa e a preservação da identidade do respondente. Em seguida, $\mathrm{o}$ instrumento foi seccionado em três partes: I) itens relacionados à identificação dos respondentes de acordo com 
os critérios populacionais estabelecidos; 2) 3 I itens que correspondiam às variáveis do modelo de pesquisa, sendo mensurados por escala Likert de I (discordo totalmente) a 7 (concordo totalmente), assim como nos estudos pioneiros (HAJLI, 20I5; DZAHABAN; SHIHAB, 20I6), e 3) itens indicativos do perfil dos respondentes, questionando -os quanto à regionalidade, idade e sexo, além de classificação socioeconômica.

Além disso, o instrumento de coleta passou por três processos de validação: tradução reversa, validação de conteúdo feita por cinco especialistas das áreas de sistemas de informação e/ou marketing e validação por pré-teste com 32 estudantes de graduação em Administração. Tais cuidados objetivaram a redução de erros de interpretação do questionário e a existência de erros tipo I (aceitação da validação do modelo de pesquisa quando este na verdade é inválido).

Por conseguinte, ao término da coleta de dados as respostas tabuladas foram submetidas ao software Statistic Package for Social Sciences (SPSS), versão 22, para resultados de estatística descritiva, que visaram a identificação e caracterização do perfil amostral e a discussão de resultados univariados dos indicadores do modelo de pesquisa. Para validação do modelo de pesquisa, os dados foram submetidos ao software livre SMART PLS, versão 3, específico para Modelagem de Equações Estruturais, que possibilita a obtenção de resultados para os parâmetros da Análise Fatorial Confirmatória (AFC): confiabilidade, validade convergente e validade discriminante. A AFC parte de especificações prévias do modelo para possibilitar a validação da estrutura proposta e dos indicadores que representam as variáveis na avaliação empírica (COHEN, 2017). Assim, os testes que compõem este tipo de análise fatorial permitem a validação do instrumento de coleta de dados e do modelo de pesquisa proposto perante a amostra obtida.

\section{ANÁLISE DE DADOS}

A seguir são apresentados os resultados encontrados pela pesquisa, de modo que inicialmente é discutida a caracterização do perfil dos respondentes e posteriormente são expostos os resultados encontrados para a análise fatorial confirmatória no processo de validação do modelo de pesquisa.

\section{Perfil amostral}

De acordo com os critérios populacionais estabelecidos, os 232 respondentes são usuários do Facebook. A procura por informações sobre compras em mídias sociais é apresentada na Tabela I, sendo a frequência mensurada por uma escala de três pontos (sempre/às vezes/nunca), além da alternativa de manter-se neutro quanto a indicação de determinada mídia social (não respondeu).

Em detrimento dos resultados expostos na Tabela I, observa-se que a maioria dos respondentes faz sempre uso das mídias sociais Google+ $(n=87=37,50 \%)$, YouTube $(n=$ $65=28,02 \%)$, Instagram $(n=62=26,72 \%)$ e Facebook $(n=37=15,95 \%)$ para buscar informações sobre o que desejam adquirir. Entretanto, somados os percentuais de busca frequente (sempre) e esporádica (às vezes), a ordem das mídias sociais mais procuradas é modificada, visto que o Facebook (n $=173=74,57 \%$ ) ocupa a primeira posição, seguido pelo YouTube $(n=162=69,83 \%)$, Instagram $(n=157=67,67 \%)$ e Google+ $(n$ $=\mid 45=62,50 \%)$. Esta análise é compatível, de certa forma, com a colocação de cada mídia social de acordo com o número de usuários brasileiros e o percentual de ativi- 
TABELA 1 - Frequência de busca de informações em Mídias Sociais

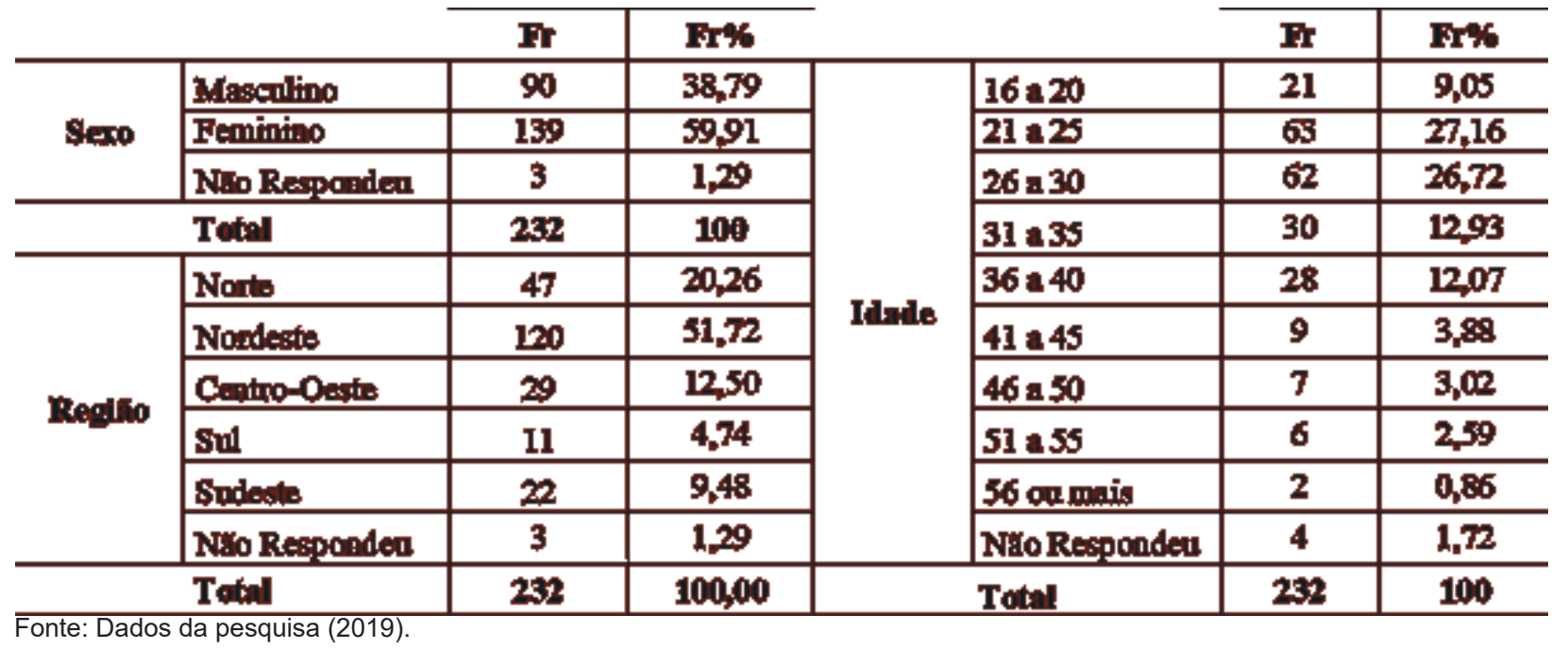

dade. Segundo dados do Hootsuite (2018), apesar do Facebook ser a mídia social com maior número de usuários, os percentuais de atividade nas mídias sociais utilizadas pelos brasileiros são de $63 \%$ para o YouTube, $62 \%$ para o Facebook, $40 \%$ para o Instagram e $38 \%$ para o Google+.

Ademais, tendo em vista a classificação e características abordadas por Ngai et al (2015) para os tipos de mídias sociais, as plataformas supracitadas e identificadas como mais utilizadas são mais propensas ao compartilhamento de conteúdo midiático (vídeos, imagens, textos) e a formação de redes sociais virtuais entre os usuários, o que pode contribuir para o engajamento dos internautas na busca por informações, comentários, opiniões sobre os mais diversos assuntos, inclusive produtos (bens de consumo e serviços).

Dentre as mídias sociais apontadas como nunca utilizadas na busca de informações, destacam-se o Twitter (87,50\%), ○ Linkedin (82,76\%) e o Pinterest (66,81\%). Como tais mídias sociais são classificadas, respectivamente, como Microblogs, Websites de Redes Sociais com intuito profissional e Websites destinados à marcação de conteúdo, acredita-se que, na percepção da amostra, o ob- jetivo principal destas mídias não esteja diretamente relacionado à comercialização e busca de informações sobre compras online.

Outras ferramentas relatadas pelos respondentes podem ser agrupadas como: sites de reclamações (Reclame Aqui), mecanismos de busca (Google, Yahoo), sites de comércio eletrônico que possuem características de mídias sociais (Netshoes, Americanas, Submarino), sites de comércio C2C (Mercado Livre, OLX) e mídias sociais ou mecanismos de conversação não listados (Skoob, Whatsapp, Blogs).

Ainda com relação aos critérios de participação na pesquisa, os respondentes foram indagados quanto a frequência anual de compras online. As respostas variaram de I a 70 vezes por ano, com uma média de aproximadamente 7 compras/ano e moda de uma compra/ano $(n=36)$. Verificou-se que a maior parte dos respondentes realiza de I a 5 compras por ano (I34 indivíduos), quase um quarto da amostra é mais experiente e compra de 6 a 10 vezes por ano (55 indivíduos) e uma minoria se apresenta como "compradores assíduos", cuja frequência de compras anuais é superior a 10 (43 indivíduos). 
Conforme o E-bit (20I8), 27,4 milhões de brasileiros fizeram pelo menos uma compra de janeiro a junho de 2018 no e-commerce, aumentando em $7,6 \%$ o volume de compras se relacionado ao primeiro semestre de 2017. Então, acredita-se que os resultados desta pesquisa apontam para indivíduos dentro desse universo, sendo que a maioria dos respondentes tem a experiência mínima com compras online, mas cujo quantitativo não se distancia muito das demais classificações (compradores experientes e assíduos).

Após a classificação dos respondentes, de acordo com os critérios populacionais, foi estabelecido o perfil sócio demográfico dos consumidores que compõem a amostra. Deste modo, a Tabela 2 apresenta os dados relacionados a sexo, faixa etária e regionalidade.

Segundo os resultados expostos na Tabela 4, dentre os 232 participantes da pesquisa, cerca de $39 \%$ são do sexo masculino, $60 \%$ do sexo feminino e $1 \%$ omitiram sua resposta à pergunta. Assim, percebe-se que a composição da amostra obteve maior participação de respondentes do sexo feminino.

Com relação à idade dos participantes, esta foi mensurada de forma livre (aberta) e posteriormente transformada em classes de faixa etária $(h=4)$ para verificação de frequência.As respostas com relação à idade variaram de 16 a 62 anos, com média de aproximadamente 29 anos e moda de 27 anos. De acordo com as classes apresentadas na Tabela 4, a maior parte dos respondentes tem 40 anos ou menos $(n=204)$, de modo que a partir dos $3 \mathrm{I}$ anos a frequência de respondentes é decrescente. A maior concentração da amostra está entre 21 e 30 anos $(n=125)$ que corresponde a mais de $50 \%$ do total.Assim, os resultados se assemelham aos achados do Hootsuite (2018) em que o maior número de usuários do Facebook corresponde à faixa etária de 18 a 34 anos.

Quanto à regionalidade, apesar dos esforços feitos na coleta de dados, houve baixo retorno quanto a auto seleção e questionários válidos em algumas regiões do Brasil. Portanto, a amostra tem alta representatividade da região Nordeste, com mais de $50 \%$ dos respondentes, seguido por uma representatividade média das regiões Norte $(20,26 \%)$, Centro-Oeste (12,5\%) e Sudeste $(9,48 \%)$ e uma representatividade baixa da região Sul (4,74\%). Nesse sentido, tal resultado só é próximo aos dados nacionais à medida que $\circ$ percentual de

TABELA 2 - Perfil Amostral

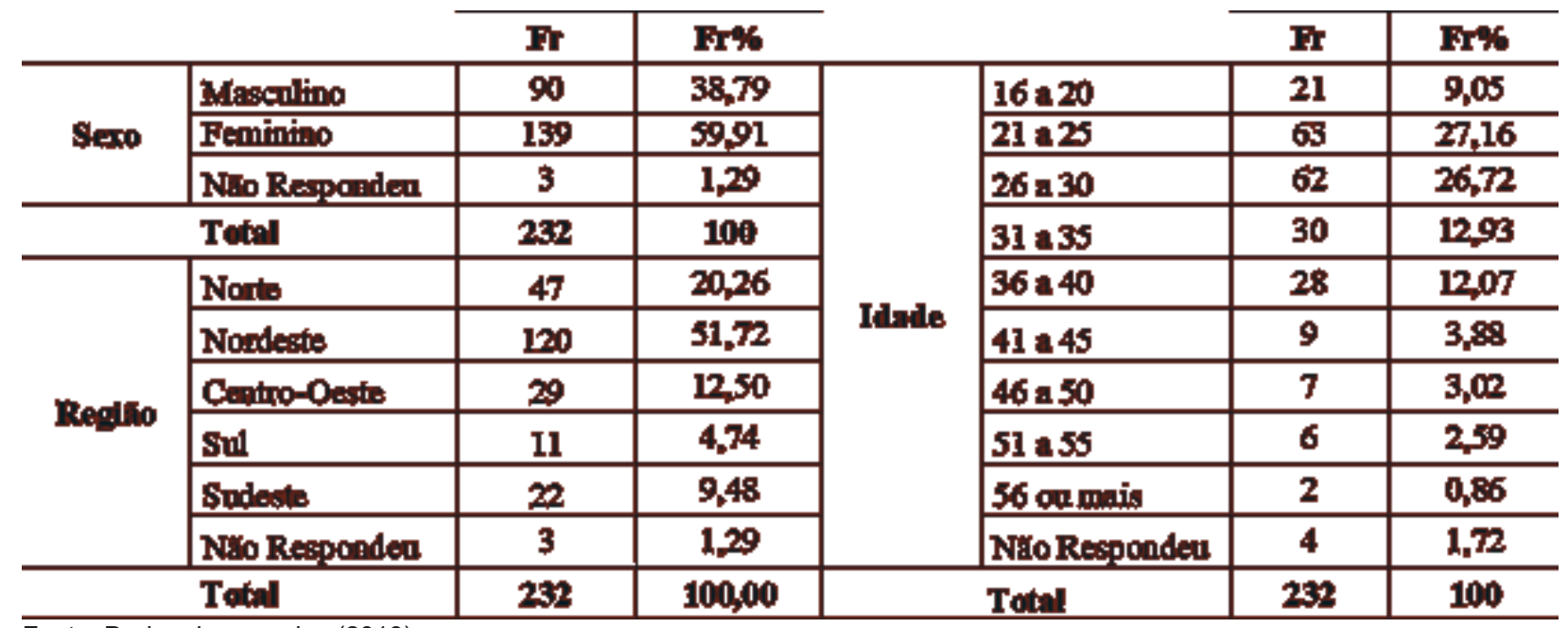

Fonte: Dados da pesquisa (2019). 
consumidores online da região Nordeste é crescente (E-BIT, 20I8).

No que diz respeito ao grau de instrução, aproximadamente $98 \%$ da amostra está acima do nível básico (ensino fundamental e médio), sendo que 96 respondentes estão cursando o nível superior, 72 respondentes estão cursando algum nível de pós-graduação (especialização, mestrado ou doutorado) e 59 respondentes tem algum nível de pós-graduação concluído. Os dados se aproximam dos achados do relatório Social Media Trends 2018 (ROCKCONTENT, 2018 ) em que $90 \%$ dos usuários de mídias sociais brasileiros tem no mínimo o nível superior em andamento. Portanto, destacase um nível adequado e elevado de escolaridade da amostra, havendo cerca de 0,8\% $(n=2)$ casos abaixo do nível médio e I,2\% $(n=3)$ casos omissos.

Quanto a renda familiar, esta foi declarada abertamente pelos respondentes, identificada e agrupada em classes de acordo com o valor do salário mínimo em $0 \mathrm{I}$ de janeiro de 2018 ( $R \$ 954,00)$. Portanto, em termos de limite inferior e superior, os valores relatados foram de $R \$ 500,00$ a $R \$ 29.000,00$ e a quantidade de residentes no domicílio variou de I a 7 pessoas. A renda familiar média foi de $\mathrm{R} \$ 4.54 \mathrm{I}, 90$, a maior parte da amostra (I0 I respondentes) declarou uma renda familiar acima de um salário mínimo até 4 salários mínimos, 96 respondentes $(41,38 \%)$ declararam uma renda acima de 4 salários mínimos e 28 respondentes $(12,07 \%)$ tem renda entre $R \$ 500,00$ (limite inferior) a um salário mínimo. Assim, a maior parte da amostra é compatível com as classes C, D e E que representam mais de $80 \%$ do quantitativo de consumidores online brasileiros (E-BIT, 2018). Ademais, dentre os casos omissos $(n=7)$, quatro respondentes não declaram renda ou quantidade de pessoas no domicílio e três respondentes declararam somente a quantidade de pessoas no domicílio.

\section{Análise fatorial confirmatória}

A investigação do modelo de pesquisa proposto por meio da análise fatorial confirmatória (AFC) permite ao pesquisador a comparação da teoria com a realidade empírica, de modo que seja possível perceber $o$ ajuste entre tais facetas (HAIR et al, 2009). Por isso, tal etapa pode ser considerada viabilizada a validade do modelo teórico e verifica quais itens da escala realmente auxiliam na estimação dos construtos.

Portanto, na AFC são verificados os resultados do modelo de pesquisa para a validade convergente, confiabilidade e validade discriminante de cada variável. Nesse sentido, a validade convergente foi medida por meio da Variância Média Extraída (VME). A VME refere-se à parcela que os indicadores convergem para explicar os construtos, sendo considerado satisfatório o resultado superior a 0,50, ou seja, a obtenção de mais de $50 \%$ de convergência (FORNELL; LARCKER, I98I; RINGLE; SILVA; BIDO, 20 I4).

A confiabilidade dos construtos foi verificada pela Confiabilidade Composta (CC). Para Hair et al (20I4), a confiabilidade composta é um parâmetro mais indicado para a análise do que a consistência interna (alfa de Cronbach) por priorizar a constatação de confiabilidade com menos vieses relacionados ao tamanho da amostra ou da escala Likert, sendo então considerado 0,7 como valor mínimo aceitável. Diante do exposto, a Tabela 3 expõe os resultados para confiabilidade e validade convergente do modelo. 
TABELA 3 - Validade Convergente e Confiabilidade

\begin{tabular}{|c|c|c|}
\hline Varlivels Latentes & $\begin{array}{c}\text { Vartincha Módh Ertrafida } \\
\text { (VMI) }\end{array}$ & Confiablidade Conaposta \\
\hline Apoio Social & 0,617 & 0,918 \\
\hline Confiança & 0,577 & 0,891 \\
\hline Componentes do Soctal Commerce & 0,530 & 0,817 \\
\hline Fhero & 0.641 & 0.899 \\
\hline Intengllo de Compura & 0,612 & 0,863 \\
\hline Presença Social & 0,594 & 0,879 \\
\hline Crittério & $>0,500$ & $>0,700$ \\
\hline
\end{tabular}

Os dados da Tabela 3 demonstram que o modelo de mensuração obteve resultados superiores aos critérios estabelecidos para validade convergente e confiabilidade. Destaca-se que as maiores cargas para VME e Confiabilidade Composta foram respectivamente dos construtos Fluxo $(0,641)$ e Apoio Social $(0,918)$. Já os menores valores resultantes foram encontrados no construto Componentes do Social Commerce, onde a VME foi de 0,530 e a Confiabilidade Composta alcançou 0,8I7.

Como última etapa do modelo de mensuração, a validade discriminante foi avaliada por meio das cargas cruzadas e do critério de Fornell-Larcker. A validade discriminante indica que os construtos e os indicadores são distintos e independentes uns dos outros (HAIR et al., 20 I4). No tangente às cargas cruzadas, Chin (1998) estabelece que as cargas fatoriais dos indicadores devem ser maiores nos construtos que estes representam do que em outros que compõem o modelo. Assim, a Tabela 4 exibe os valores para as cargas fatoriais de cada indicador (linhas) para todos os construtos (colunas) do modelo, sendo destacada a carga mais alta encontrada.

Observando os resultados da Tabela 4 é possível atestar que as cargas fatoriais de cada indicador são maiores em seus respectivos construtos, sendo inferiores a 0,500 para os demais construtos, o que garante a validade discriminante e demonstra que os itens de construto não pertencem a duas variáveis latentes ao mesmo tempo, ou seja, contribuem fortemente para a mensuração dos construtos aos quais se destinam.

Ainda sobre a validade discriminante, por meio do critério de Fornell e Larcker (I98I) a constatação da diferença entre as variáveis latentes ocorre quando as raízes quadradas das VMEs de cada construto são superiores às correlações de Pearson entre os construtos, conforme demonstrado na Tabela 5.

Mais uma vez a validade discriminante é garantida perante os resultados expostos, onde as raízes da VME (valores em negrito) são superiores às correlações das variáveis latentes. Em conformidade com os resultados apontados na validade convergente, a maior e menor raiz da VME correspondem, respectivamente, aos construtos Fluxo $(0,800)$ e Componentes do Social Commerce $(0,728)$. No tocante às correlações entre os construtos, de acordo com Cohen (1988), estas podem ser consideradas como fortes (de I,000 a 0,500), moderadas $(0,490$ a 0,300$)$ e fracas $(0,290$ a 
TABELA 4 - Cargas Cruzadas

\begin{tabular}{|c|c|c|c|c|c|c|}
\hline & $\begin{array}{l}\text { Apolio } \\
\text { Sodial }\end{array}$ & Continga & $\begin{array}{l}\text { Conpenertes } \\
\text { do Soelat } \\
\text { Counuence }\end{array}$ & Fino & $\begin{array}{c}\text { Intencilio de } \\
\text { Compra }\end{array}$ & $\begin{array}{c}\text { Presençat } \\
\text { Socinil }\end{array}$ \\
\hline C:H1 & 0,363239 & 0,714851 & 0,248008 & 0,245982 & 0,429792 & 0.467458 \\
\hline CE2 & $0,2,7095$ & 0,798822 & 0,090957 & 0,214581 & 0,27021 & 0,38581 \\
\hline CIS & 0,290163 & 0,679967 & 0,238302 & 0,333729 & 0,391369 & 0,182598 \\
\hline CF4 & 0,120498 & 0,759096 & 0,136198 & 0,24211 & 0,275456 & 0,238227 \\
\hline CEs & 0,102487 & 0,773151 & 0,139947 & 0,210349 & 0,254661 & 0,217674 \\
\hline CE6 & 0,125664 & 0,82118 & 0,172607 & 0,246663 & 0,370008 & 0,3000981 \\
\hline Csc1 & 0,199856 & 0,272316 & 0,631161 & 0,133413 & $0,2287,02$ & 0,199213 \\
\hline $\csc 2$ & 0,33882 & 0,182357 & 0,721164 & 0,280771 & 0,387383 & 0,167189 \\
\hline $\csc s$ & 0,365386 & 0,12828 & 0,815752 & 0,245808 & 0,310603 & 0,111315 \\
\hline Csc4 & 0,293019 & 0,146925 & 0,732485 & 0,299283 & 0,256162 & 0,206085 \\
\hline FLI & 0,401633 & 0,252942 & 0,299412 & 0,745024 & 0,21923 & 0,347991 \\
\hline FL & 0,267876 & 0,247011 & 0,195055 & 0,825364 & 0,275838 & 0,287882 \\
\hline Fis & 0,274204 & 0,273117 & 0,300035 & 0,842251 & 0,368715 & 0,290204 \\
\hline FI4 & 0,286986 & 0,261186 & 0,140141 & 0,770933 & 0,268541 & 0,278527 \\
\hline ILS & 0251299 & 0,29392 & 0,321678 & 0,814211 & 0401618 & 0,304281 \\
\hline ICA & 0,346671 & 0,413019 & 0,355105 & 0,310084 & 0,79746 & 0,270351 \\
\hline IC2 & 0,318936 & 0,349619 & 0,33243 & 0,326461 & 0,815583 & 0,224613 \\
\hline ICS & 0,358475 & 0,324200 & 0,408417 & 0,381791 & 0,807787 & 0,210365 \\
\hline IC4 & 0,248012 & 0,321989 & 0,18742 & 0,189448 & 0,702071 & 0,201942 \\
\hline P:I & 0,292652 & 0,227835 & 0,106199 & 0,256547 & 0,194922 & 0,752228 \\
\hline PS2 & 0,406642 & 0,339089 & 0,150094 & 0,258173 & 0,241404 & 0,783014 \\
\hline $\mathrm{Fs3}$ & 0,371332 & 0,394248 & 0,184434 & 0,380289 & 0,259213 & 0,840348 \\
\hline F84 & 0,400001 & 0,356552 & 0,260362 & 0,250237 & 0,258715 & 0,750926 \\
\hline Pss & 0,368142 & 0,24757 & 0,158820 & 0,294411 & $0,170 \mathrm{~s} s 1$ & 0,721057 \\
\hline sid & 0,843842 & 0,240996 & 0,346095 & 0,334457 & 0,319947 & 0,424221 \\
\hline 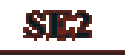 & 0,849301 & 0,250723 & 0,348557 & 0,300212 & 0251561 & 0,390161 \\
\hline $\mathbf{S B}$ & 0,726621 & 0,298955 & 0,167361 & 0,29428 & A,309875 & 0,456042 \\
\hline sty & 0,731027 & 0,275338 & 0,270697 & 0,249421 & 0,333186 & 0,427311 \\
\hline SI1 & 0,731874 & 0,172132 & 0,45971 & 0,329605 & 0,356099 & 0,280557 \\
\hline \$12 & 0,793977 & 0,171359 & 0,361353 & 0255378 & 0380095 & 0295801 \\
\hline st3 & 0,810663 & 0,187866 & 0,361901 & 0,279302 & 0,304909 & 0,349994 \\
\hline
\end{tabular}

Fonte: Dados da pesquisa (2019).

0,100). Assim, nota-se que as correlações resultantes são consideradas como moderadas ou fracas.

Dentre as correlações moderadas, destaca-se os resultados para a Intenção de Com- pra que aparentemente possui boa parte das correlações mais altas da Tabela 5. A variável latente Presença Social abarca a correlação mais fraca e a mais forte do modelo de pesquisa, respectivamente, com Componentes 
TABELA 5 - Validade Discriminante por Fornell e Larcker (1981)

\begin{tabular}{|c|c|c|c|c|c|c|}
\hline & $\begin{array}{l}\text { Apdo } \\
\text { Soctal }\end{array}$ & Conllange & $\begin{array}{l}\text { Componentes } \\
\text { dostocint } \\
\text { Commeres }\end{array}$ & Fhro & $\begin{array}{c}\text { Intergise de } \\
\text { Coinpre }\end{array}$ & $\begin{array}{l}\text { Preseng } \\
\text { Bod:al }\end{array}$ \\
\hline Apolo siodal & 0,785 & & & & & \\
\hline Conflingen & 0293 & $0,7=9$ & & & & \\
\hline $\begin{array}{l}\text { Componentes } \\
\text { do Soctort } \\
\text { Commeres }\end{array}$ & 0,421 & 0,238 & 0,728 & & & \\
\hline Inton & 0,373 & 0,334 & 0326 & 0,800 & & \\
\hline $\begin{array}{c}\text { Intengtio de } \\
\text { Ceninga }\end{array}$ & $0,40 s$ & 0,455 & 0,413 & 0,387 & 0,782 & \\
\hline $\begin{array}{c}\text { Presenca } \\
\text { Soclill }\end{array}$ & 0,481 & 0,415 & 0,229 & 0,380 & 02296 & 0,71 \\
\hline
\end{tabular}

Fonte: Dados da pesquisa (2019).

do Social Commerce $(0,229)$ e Apoio Social $(0,48 \mathrm{I})$, o que fortalece a proposta de Zhang et al (20l4) quanto à experiência do consumidor online e infere ressalvas para a associação entre a manifestação de identidade virtual e as ferramentas disponíveis para tal.

Diferindo das proposições teóricas de Hajli (20I5), a correlação entre Componentes do Social Commerce e Confiança é considerada fraca $(0,238)$, ou seja, a percepção de confiança pode ter pouco a ver com as funcionalidades dispostas pela plataforma de mídias sociais. Porém, a Confiança possui associações mais relevantes com a Intenção de Compra $(0,455)$, Presença Social $(0,4 I 5)$ e Fluxo $(0,334)$, o que reforça as noções de que há relações entre a confiança e a experiência do consumidor online e que sem confiança a propensão ao comportamento de compra é pequena.

Ademais, observa-se que os resultados das correlações poderiam ser superiores caso o tamanho da amostra fosse maior e a distribuição dos dados fosse normal (já que Correlações de Pearson é um teste indicado para dados paramétricos). Porém, apesar da distribuição não normal dos dados, a apreciação das correlações é uma consideração válida para inferências sobre o possível comportamento dos dados e das relações do modelo de pesquisa.

Em suma, a análise fatorial confirmatória do modelo de pesquisa permitiu a validação da estrutura sem a exclusão de indicadores ou variáveis, de modo que toda a estrutura e caminhos traçados no modelo foram confirmados e são considerados aceitáveis para a intenção de compra dos consumidores brasileiros.

\section{CONCLUSÃO}

As mídias sociais obtiveram destaque nos últimos anos ao proporcionar uma forma diversificada de relacionamento dos indivíduos. Estas também possibilitaram a mudança no envolvimento interacional dos consumidores na internet, 0 que promoveu o surgimento de um novo 
fluxo de comércio eletrônico denominado social commerce.

Acadêmicos e profissionais ainda buscam entender tal fenômeno e o que leva os usuários/consumidores à sua adoção, investigando aspectos de design das plataformas, modelos de negócio, políticas de segurança, estratégias empresarias e de adoção organizacional, desempenho de empresas envolvidas, comportamento dos usuários, dentre outras perspectivas. Nesse sentido, a presente pesquisa buscou validar uma proposta teórica para a adoção de social commerce, baseada em Hajli (20I5) e Dzahaban e Shihab (20I6), que resulte na intenção de compra em mídias sociais por parte dos usuários brasileiros. $O$ processo de adoção evidenciado pelo modelo de pesquisa levou em consideração a influência dos componentes do social commerce, a experiência do consumidor online em termos de apoio social, presença social e fluxo e a confiança gerada entre as partes envolvidas (consumidores, vendedores, organizações, demais usuários etc.). Assim, expandiu-se o contexto dos modelos pioneiros para um modelo de pesquisa que pudesse representar ambos e determinar de forma eficiente a intenção de compra.

Em suma, os resultados encontrados mostraram-se satisfatórios, considerando todas as etapas de análise dos dados. Verificou-se que a estrutura foi validada sem perdas o que além de ser positivo para as intenções da pesquisa também reforça as proposições dos estudos pioneiros sobre as relações entre as variáveis estudadas.

Consequentemente, os achados da pesquisa demonstram caminhos aceitáveis para o consumidor online brasileiro, validando um modelo no qual um conjunto de ferramentas que compõem as mídias sociais conseguem facilitar a experiência do consumidor online, de modo que tal experiência tenha um papel mediador chave na confiança e a intenção de compra seja alcançada. Portanto, concorda-se com Lu, Fan e Zhou (2016) que o contexto do consumidor para a intenção comportamental no social commerce depende tanto de condições estruturais quanto de fatores sociais ambientados.

Acredita-se que o amadurecimento das plataformas de mídias sociais tem sofrido maior influência do comportamento dos usuários do que das estratégias empresariais relacionadas à inovação incremental de tais plataformas. Apesar do objetivo maior das mídias sociais ser o relacionamento entre os indivíduos, a usabilidade expandiu-se para novos contextos e é correto afirmar que o sucesso crescente da geração de atividades comerciais em ambientes online socializados é decorrente da aceitação e envolvimento dos usuários nesta perspectiva.

Por fim, apesar dos resultados positivos do estudo, de certo, limitações e contribuições futuras podem ser citadas. Em virtude das decisões metodológicas adotadas, os resultados não possuem caráter generalista, de modo que novas propostas devem surgir para reforçar os achados. Também se destaca que a amostra obteve baixa representatividade em algumas regiões brasileiras e por isso tais regiões devem ser melhor exploradas em novos estudos.Ademais, este estudo não verificou a confirmação das relações hipotetizadas no modelo teórico, já que o objetivo da pesquisa consistia na validação da estrutura. Desta forma, novos estudos podem explorar as influências propostas, determinando de forma mais profunda quais variáveis são mais relevantes para a construção da intenção de compra no social commerce. 


\section{REFERÊNCIAS}

BAGHDADI, Y. A framework for social commerce design. Information Systems, v. 60, n. I, P. 95II3, 2016.

BARRETO, R. de M. M. Direito, redes sociais e social commerce: pensando a proteção do consumidor. Revista da Seção Judiciária do Rio de Janeiro, v. 18, n. 32, p. I45- I62, 201 I.

BUSALIM, A. H.; HUSSIN, A. R. Understanding social commerce: A systematic literature review and directions for further research. International Journal of Information Management, v. 36, n. 6, p. 1075-1088, 2016.

CGI. TIC DOMICÍlIOS: Pesquisa Sobre o Uso das Tecnologias de Informação e Comunicação nos Domicílios Brasileiros 2017. 2018. Disponível em: < https://www.cgi. br/publicacao/pesquisa-sobre-o-uso-das-tecnologias-de-informacao-e-comunicacao-nos-domicilios -brasileiros-tic-domicilios-20 I 7/ >. Acesso em: 3 dez. 2018.

CHEN, Y. Y. et al. The effect of integrating social plugins into e-commerce website: a study on online consumer behaviour. In: International Conference on Ubiquitous Information Management and Communication, $7^{\text {th }}, 2013$. Proceedings... ACM, 20I3. p. I-6.

CHEN, J.; SHEN, X-L.; CHEN, Z-J. Understanding social commerce intention:A relational view. In: Hawaii International Conference on System Sciences (HICSS), 47 $7^{\text {th }}$, Hawaii, 20l4. Proceedings... Hawaii: IEEE, 20I4. p. I793- 1802.

CHIN,W.W.The partial least squares approach for structural equation modeling. In: Marcoulides, G.A. (Ed.). Modern methods for business research. London: Lawrence Erlbaum Associates, p. 295-236, 1998.
COHEN, J. Statistical Power Analysis for the Behavioral Sciences. 2. ed. New York: Lawrence Erlbaum Associates, 1988.

COHEN, E. D.Validação de Escalas de Mensuração para Diagnóstico e Gestão. In: Encontro da ANPAD EnANPAD, XLI, 20I7, São Paulo. Anais... São Paulo: ANPAD, 20I7. p. I- I 7.

CURTY, R. G.; ZHANG, P. Social commerce: Looking back and forward. In: Association for Information Science and Technology - ASIST, New Orleans, 20II. Proceedings... New Orleans: ASIST, 20II. p. $1-10$.

DZAHABAN, D.; SHIHAB, M. R. Customer social experience as antecedents of social commerce: Insights from Kaskus. In: International Conference on Advanced Computer Science and Information Systems (ICACSIS), $8^{\text {th }}, 2016$, Malang. Proceedings... Malang: IEEE, 20 I6. p. 25 I-256.

E-BIT. Webshoppers $38^{a}$ edição. 2018. Disponível em: <https:// www.ebit.com.br/webshoppers>. Acesso em: 24 jan. 2019.

FORNELL, C.; LARCKER, D.F. Evaluating structural equation models with unobservable variables and measurement error. Journal of Marketing Research. v.18, n. I, p. 39-50, 1981.

FRIEDRICH, T. Analyzing the Factors that Influence Consumers' Adoption of Social Commerce - A Literature Review. In: Americas Conference on Information Systems, Twenty-first, Puerto Rico, 2015. Proceedings... Puerto Rico: Americas Conference on Information Systems, 2015. p. I-16

GALINARI, R. et al. Comércio eletrônico, tecnologias móveis e mídias sociais no Brasil. BNDES Setorial, Rio de Janeiro, n. 4I, p. I35-
I80, $20 \mid 5$.

HAIR, J. F. et al. Análise multivariada de dados. 6. ed. Porto Alegre: Bookman, 2009.

HAIR, J. F. et al. A primer on partial least squares structural equation modeling (PLS-SEM). Los Angeles: Sage Publications, 2014.

HAJLI, N.A.The role of social support on relationship quality and social commerce. Technological Forecasting and Social Change, v. 87 , p. 17-27, 20|4a.

Social commerce for innovation. International Journal of Innovation Management, v. I8, n. 04, p. I -24, 20 I4b.

Social commerce constructs and consumer's intention to buy. International Journal of Information Management, v. 35, n. 2, p. I83-191, 2015. HAJLI, N.; FEATHERMAN, M. S. Social commerce and new development in e-commerce technologies. International Journal of Information Management, v. 3, n. 37, p. I77-178, 2017.

HAJLI, N. et al. A social commerce investigation of the role of trust in a social networking site on purchase intentions. Journal of Business Research, v. 7I, p. I33141, 2017.

HOOTSUITE. Digital in 2018 in Southern America. Disponível em: <https://pt.slideshare.net/ wearesocial/digital-in-2018-insouthern-america-part-I-north-86863727>. Acesso em: 23 jan. 2018.

HUANG, Z.; BENYOUCEF, M. From e-commerce to social commerce: A close look at design features. Electronic Commerce Research and Applications, v. 12, n. 4, p. 246-259, 2013.

IBM. Social Commerce Defined. 2009. Disponível em: <https:// 
digitalintelligencetoday.com/documents/IBM2009.pdf>. Acesso em: 12 nov. 2017.

KAPLAN,A. M.; HAENLEIN, M. Users of the world, unite! The challenges and opportunities of Social Media. Business horizons, v. 53, n. I, p. 59-68, 2010.

KIM, S.; PARK, H. Effects of various characteristics of social commerce (s-commerce) on consumers' trust and trust performance. International Journal of Information Management, v. 33, n. 2, p. 318-332, 2013.

LI, C.-Y. How social commerce constructs influence customers' social shopping intention? An empirical study of a social commerce website. Technological Forecasting and Social Change. 2017. Disponível em < https://doi.org/l0.1016/j.techfore.2017.1 I.026 >.Acesso em: 22 mar. 2018.

LIANG, T-P.;TURBAN, E. Introduction to the special issue social commerce: a research framework for social commerce. International Journal of electronic commerce, v. 16, n. 2, p. 5-14, 201 I.

LIANG,T.-P.et al.What drives social commerce:The role of social support and relationship quality. International Journal of Electronic Commerce, v. I6, n. 2, p. 69-90, 201 I.

LIN, X.; LI, Y.; WANG, X. Social commerce research: Definition, research themes and the trends. International Journal of Information Management, v. 37, n. 3, p. 190-201, 2017.

LU, B.; FAN, W.; ZHOU, M. Social presence, trust, and social commerce purchase intention: An empirical research. Computers in Human Behavior, v. 56, p. 225-237, 2016.

MALITA, L. Social media time management tools and tips. Procedia Computer Science, v. 3, p. 747753, 2011.
MANGOLD, W. G.; FAULDS, D. J. Social media: The new hybrid element of the promotion mix. Business horizons, v. 52, n. 4, p. 357-365, 2009.

MARSDEN, P. Speed Summary | Wired Feb 20II Cover Story on Social Commerce. 20II. Disponível em: https://digitalintelligencetoday.com/speed-summary-wired-feb-20 I I-cover-story-on-social-commerce. Acesso em: 06 mar. 2018

MENTI, J. F. et al. Fatores Motivadores da Participação em Social Commerce: um Estudo com Usuários Brasileiros. In: Encontro de Administração da Informação - EnADI, VI, 2017. Curitiba. Anais... Curitiba:ANPAD, 2017. p. I-9.

NGAI, E.W.T. et al. Social media models, technologies, and applications: an academic review and case study. Industrial Management \& Data Systems, v. I I5, n. 5, p. 769-802, 2015.

NGAI, E.W.T.; TAO, S. S. C.; MOON, K. K. L. Social media research: Theories, constructs, and conceptual frameworks. International Journal of Information Management, v. 35, n. I, p. 33-44, 20 I 5. RINGLE, C. M.; SILVA, D.; BIDO, D. de S. Modelagem de Equações Estruturais com Utilização do Smartpls. Revista Brasileira de Marketing, v. I3, n. 2, p. 56-73, 2014.

ROCKCONTENT. Social Media Trends 2018. Disponível em: $<$ https://materiais.rockcontent. com/social-media-trends>. Acesso em: 03 dez. 2018.

ROSA, R. A.; DOLCI, D. B.; LUNARDI, G. L. Social Commerce: Estado da Arte e Oportunidades de Pesquisa. In: Encontro da Anpad EnANPAD, XXXVIII, 20I4, Rio de Janeiro. Anais... Rio de Janeiro: ANPAD, 20I4. p. I-I6.
SAUNDERS, M.; LEWIS, P.; THORNHILL, A. Research methods for business students. 5. ed. Edimburg: Pearson Education India, 2009.

SAUNDAGE, D.; LEE, C. Y. Social commerce activities-a taxonomy. In: Australasian Conference on Information Systems, 22 ${ }^{\text {nd }}, 201 \mathrm{I}$, Sydney. Proceedings... ACIS 20II: Identifying the information systems discipline, 20 I I. p. I-9.

SAMPIERI R. H.; COLLADO C. F.; LUCIO P. B., Metodología de la investigacion. 4. ed. México: Mac Graw Hill, 2006.

SHANMUGAM, M. et al. The applications of social commerce constructs. International Journal of Information Management, v. 36, n. 3, p. 425-432, 2016.

TURBAN et al. Electronic Commerce 2018. Springer International Publishing, 2018.

TURBAN, E.; STRAUSS, J.; LAI, L. Social Commerce: Marketing, Technology and Management. Springer International Publishing, 2016. TODRI,V.;ADAMOPOULOS, P. Social commerce:An empirical examination of the antecedents and consequences of commerce in social network platforms. In: International Conference on Information Systems, Thirty Fifth, 2014, Auckland. Proceedings... Auckland: International Conference on Information Systems, 2014. p. I-I8.

WANG, C.; ZHANG, P.The evolution of social commerce: The people, management, technology, and information dimensions. Communications of the Association for Information Systems (CAIS), v. 3 I , p. 105-127, 2012.

WU, J. et al. The research of design based on social commerce. International Journal of Social Science Studies., v. 3, p. I57165, 2015. 
YADAV, M. S. et al. Social commerce: a contingency framework for assessing marketing potential. Journal of Interactive Marketing, v. 27, n. 4, p. 3 II-323, 20 I 3.

ZHANG, $H$. et al. What motivates customers to participate in social commerce? The impact of technological environments and virtual customer experiences. Information \& Management, v. 5I,n. 8, p. I0I7-1030, 2014. 